\title{
Quartzito azul com dumortierita e fosfatos de alumínio do Espinhaço setentrional, Bahia: mineralogia e petrogênese
}

\author{
Hanna Jordt Evangelista ${ }^{{ }^{*}}$, André Danderfer Filho ${ }^{2}$
}

\begin{abstract}
Resumo No domínio fisiográfico setentrional da Serra do Espinhaço, na Bahia, o quartzito azul é minerado como rocha ornamental de grande valor. As lentes métricas a decamétricas estão irregularmente distribuídas dentro de quartzitos esbranquiçados pertencentes à Formação Vereda. Estudos óticos e análises de microssonda identificaram dumortierita, cianita, muscovita cromífera e lazulita como os principais minerais responsáveis pelas cores azuladas a esverdeadas. Fosfatos como troleítta, augelita, svanbergita-goyazita e monazita ocorrem esporadicamente. Dumortierita e cianita, que são os mais abundantes minerais causadores de cor, estão concentrados majoritariamente em estratos sedimentares plano-paralelos a cruzados de largura milimétrica. A dumortierita é também encontrada preenchendo fraturas discordantes, evidenciando a elevada mobilidade de boro durante o metamorfismo. As condições metamórficas estimadas de $\mathrm{P} \geq 3,5$ kbar e $\mathrm{T}=475$ a $560{ }^{\circ} \mathrm{C}$ são da fácies xisto verde superior a anfibolito inferior. Grãos de quartzo arredondados herdados do protólito sedimentar são conspícuos na porção Norte e estão ausentes na porção Sul da área estudada, o que indica intensidade de deformação crescente para Sul. Em termos de ambiente deposicional, a litofácies da Formação Vereda é interpretada como o produto inicial do preenchimento de um rift mesoproterozoico, associado a ambientes lagunares e planícies de maré em sistemas continentais e costeiros, nos quais o boro que gerou dumortierita pode ter sido concentrado em sedimentos com contribuição de material evaporítico.
\end{abstract}

Palavras-chave: Espinhaço; mineralogia; quartzito azul; dumortierita; fosfatos; petrogênese.

Abstract Blue quartzite with dumortierite and aluminum phosphates from the Northern Espinhaço, Bahia: mineralogy and petrogenesis. In the Northern physiographic domain of the Espinhaço Ridge, in Bahia State, Brazil, blue quartzite is mined as a valuable dimension stone. The meter- to decameter-sized lenses are irregularly distributed within the whitish quartzites belonging to the Vereda Formation. Optical studies and microprobe analyses have identified dumortierite, kyanite, chromium-bearing muscovite, and lazulite as the main minerals responsible for the bluish and greenish colors. Phosphates, such as trolleite, augelite, svanbergite-goyazite and monazite, occur sporadically. Dumortierite and kyanite, the most abundant color-causing minerals, are mostly concentrated along millimeter-wide, plane-parallel to crossed sedimentary beds. The dumortierite is also found filling discordant fractures, evidencing the high mobility of boron during metamorphism. The estimated metamorphic conditions of $\mathrm{P} \geq 3.5 \mathrm{kbar}$ and $\mathrm{T}=475$ to $560^{\circ} \mathrm{C}$ are of higher greenschist to lower amphibolite facies. Rounded quartz grains inherited from the sedimentary protolith are conspicuous in the Northern part and absent in the Southern region of the studied area, which indicates increasing deformation southwards. In terms of the depositional milieu, the lithofacies of the Vereda Formation is interpreted as the initial filling product of a Mesoproterozoic rift associated with alluvial planes and lagoons or tidal planes in continental and coastal systems, where the boron that generated dumortierite could have been concentrated in sediments with contribution of evaporitic material.

Keywords: Espinhaço; mineralogy; blue quartzite; dumortierite; phosphates; petrogenesis.

INTRODUÇÃO A importância do quartzito azulado da Serra do Espinhaço Setentrional, na Bahia, comercializado sob o nome de "Azul Macaúbas" e suas variedades "Azul Boquira" e "Azul Imperial”, vem crescendo no mercado internacional, apresentando um grande potencial como fonte de divisas para o Brasil. Cassedanne \& Franco (1966) e Cassedanne et al. (1989) foram pioneiros na caracterização química e mineralógica de alguns aluminofosfatos e aluminoborosilicatos presentes nos quartzitos da Bahia, descrevendo as características da dumortierita e lazulita, minerais que causam a cor azulada da rocha. Fleischer (1971), por meio de estudos petrográficos, estratigráficos e estruturais na escala macro e mesoscópica, descreveu a dumortierita concentrada nos planos primários do acamamento, dispersa uniformemente ou em veios e manchas na rocha. Morteani \& Ackermand (2004) aprofundaram os estudos químicos e mineralógicos de quartzitos da Bahia, sem, no entanto, entrar em detalhes do ambiente geológico/estratigráfico, o qual constitui um enigma na evolução da bacia Espinhaço. Quartzitos com mineralogia semelhante são também encontrados na região de 
Diamantina, em Minas Gerais, na porção meridional da Serra do Espinhaço, conforme relatado por Horn et al. (1996, 2000) e Morteani et al. (2001).

Opresente trabalho reportou os resultados dos estudos mineralógicos em quartzitos de tonalidades azuladas e esverdeadas, coletados na porção Norte do Espinhaço Setentrional e provenientes da Formação Veredas (Fig. 1), com o objetivo de melhor caracterizar o ambiente de formação e tecer considerações sobre a causa da variação de cor e a origem dos minerais presentes em tais rochas.

\section{LOCALIZAÇÃO, GEOLOGIA, ESTRATIGRA-}

FIA As ocorrências de quartzitos azuis se encontram distribuídas ao longo de uma faixa preferencial de direção NNW-SSE, com extensão superior a 100 km e largura que varia de 500 a $2000 \mathrm{~m}$, na parte oriental da Serra do Espinhaço setentrional (Fig. 1). O horizonte estratigráfico ao qual pertencem foi cartografado nos trabalhos de Schobbenhaus (1972), Moutinho da Costa \& Silva (1980) e Danderfer (2000). De acordo com a proposta de Danderfer \& Dardenne (2002), as rochas investigadas ocorrem no terço médio da Formação Veredas, reconhecida apenas no prolongamento setentrional da Serra do Espinhaço, na base do Grupo Sítio Novo do Supergrupo Espinhaço. No contexto geotectônico, este segmento materializa a porção Ocidental do corredor de deformação do Paramirim (Alkmim et al. 1993), Norte do cráton do São Francisco (Almeida 1977), e remonta parte da bacia Espinhaço. O único evento tectonometamórfico caracterizado na região sucedeu no Ediacariano, entre 650 e $500 \mathrm{Ma}$, relacionado com as colagens Pan-Africano/ Brasiliano (Schobbenhaus 1996, Danderfer 2000).

$\mathrm{O}$ arcabouço tectônico do Espinhaço setentrional é marcado, essencialmente, por um padrão estrutural de orientação preferencial NNW-SSE, no qual caracteriza-se um sistema de dobras e falhas de abrangência regional, que se encontra presente nas rochas da cobertura e em parte do seu embasamento (Schobbenhaus 1996, Danderfer 2000). A Formação Veredas ocorre nos blocos tectônicos de Boquira, a Leste, e de Ibotirama, a Oeste, separados pela falha de Santo Onofre que atravessa a área com direção NNW-SSE. O limite inferior dessa unidade, definido por discordância regional, é assinalado por erosão profunda das partes superiores do Grupo São Marcos (Danderfer \& Dardenne 2002) e diagnosticado em boa parte por meio de conglomerados basais, assim como por uma descontinuidade na deposição entre as unidades. Já o seu contato com as formações Viramundo e Garapa, intervalo superior do Grupo Sítio Novo, é salientado em boa parte da área por uma passagem gradacional.
O Grupo Sítio Novo define o preenchimento volumoso de um rifte assimétrico, com eixo NNW$\mathrm{SSE}$, em que o preenchimento inicial é registrado por rochas da Formação Veredas (Danderfer 2000, Danderfer e Dardenne 2002). Essa unidade corresponde ao Membro Vereda de Schobbenahus (1972) e integra a 'Unidade Serra das Veredas' e a porção superior da 'Unidade Fazendinha' (subunidade 2), como estabelecido por Moutinho da Costa \& Silva (1980). Nela, registram-se fácies de granulação grossa a muito grossa, definidas por conglomerados desorganizados ou interestratificados com arenitos, às vezes formando arranjos com estratificação cruzada acanalada bem evidente. As fácies arenosas correspondem a metarenitos com estratificações cruzadas de grande porte a gigantes, laminação planar, sigmoidal e horizontal a cruzada planar de baixo ângulo, assim como a metarenitos maciços e com laminação cruzada cavalgante a horizontal; metarenito com seixos com estratificações diversas são comuns em determinadas partes da unidade. Uma descrição mais pormenorizada dessas fácies foi apresentada em Danderfer (2000), que interpreta o cenário deposicional da Formação Veredas associado ao preenchimento inicial de um rifte, com desenvolvimento de sistemas continentais e litorâneos. De acordo com Danderfer (2000), as litofácies de cor azulada são representadas por metarenitos com laminação cruzada e lamitos interestratificados, originados pela sedimentação em ambientes lagunares ou em planícies de marés situadas na parte posterior das ilhas barreiras. Nesse contexto, ter-se-iam depositado evaporitos constituindo a fonte de boro para a dumortierita.

MATERIAIS E MÉTODOS Trabalhos de campo e coleta de amostras foram realizados no escopo de Danderfer (2000). A localização dos exemplares investigados está indicada no mapa da Fig. 1 (pontos V77, V43, V76, V8, V35, V58 e V38). Em adição, analisou-se uma amostra de metarenito verde da Formação Fazendinha (Grupo São Marcos; ponto F1). Análises de química mineral por microssonda eletrônica de varredura foram realizadas no Laboratório do Instituto de Geociências da Universidade Federal do Rio Grande do Sul em equipamento Cameca SX50, operado em condições analíticas de $15 \mathrm{kv}$, corrente de $10 \mathrm{n} \AA$ e tempo de contagem de 30 segundos. Análises por microscopia eletrônica de varredura com sistema de energia dispersiva (MEV/SED) foram realizadas no Departamento de Geologia da Universidade Federal de Ouro Preto em equipamento JEOL JSM5510. 

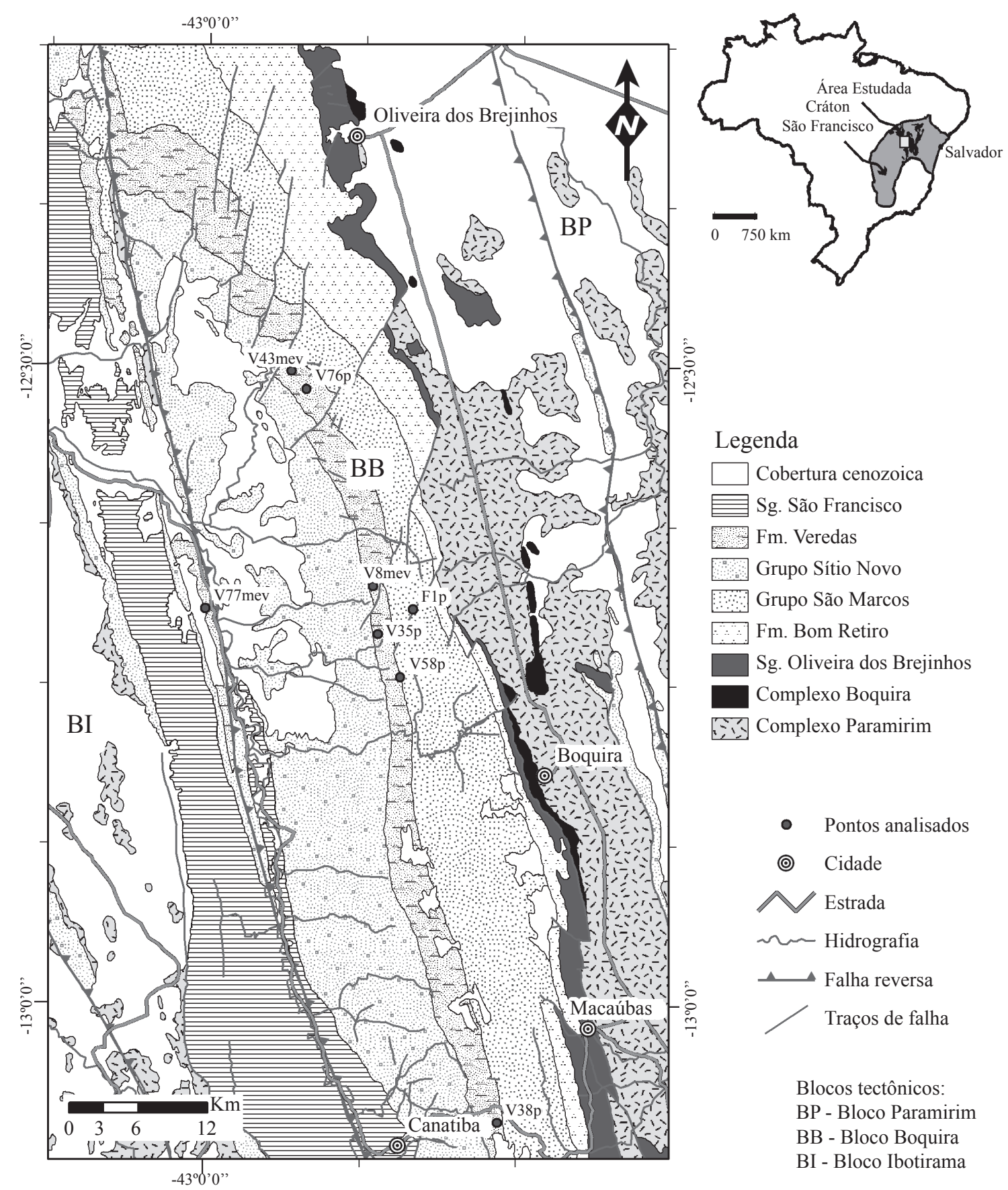

Legenda
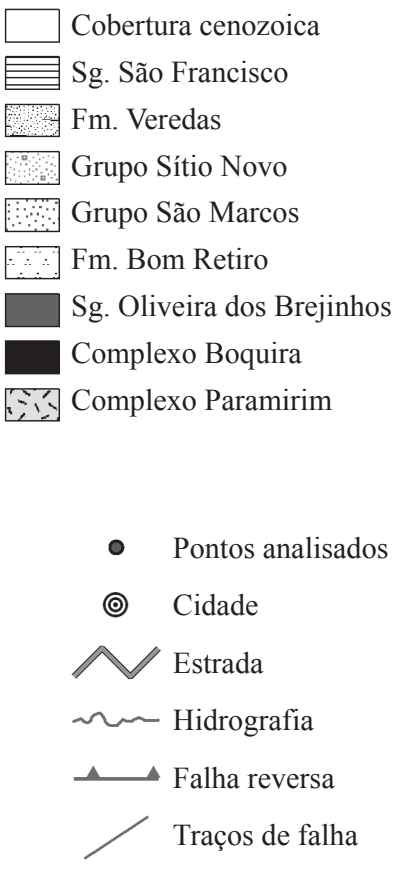

Blocos tectônicos: BP - Bloco Paramirim BB - Bloco Boquira BI - Bloco Ibotirama

Figura 1 - Mapa geológico simplificado com localização dos pontos analisados (modificado de Danderfer 2000).

PETROGRAFIA O quartzito típico da Formação Vereda na região estudada tem, mais comumente, cor esbranquiçada a acinzentada. Localmente, existem lentes e camadas coloridas em tonalidades de azul, verde-azuladas e verdes, remontando horizontes econômicos de alguns metros (Figs. 2A e 2B). Comparando-se rochas da porção setentrional com as da meridional em termos microestruturais, verifica-se que, ao Norte (pontos V43 e V76), o quartzo arredondado, de origem detrítica, é comum, coexistindo com quartzo metamórfico mais fino, produto de recristalização metamórfica parcial. Mesmo nas amostras com sericita, a foliação metamórfica é inexistente ou muito incipiente. Na porção central (pontos V8, V35 e V58), o quartzo foi recristalizado e exibe microestrutura poligonal, interlobada ou suturada. Porém, a forma arredondada original dos grãos detríticos ainda pode ser reconhecida localmente pela preservação da película de sericita envolvendo os limites dos antigos grãos. A recristalização metamórfica marginal por migração de borda de grão gerou contatos suturados, os quais se deslocaram para além dos 
limites dos grãos originais. Mais a Oeste (ponto V77), o quartzo foi inteiramente recristalizado, adquirindo microestrutura poligonal a interlobada. Mica exibe orientação preferencial responsável pela nítida foliação. Na amostra V38, o quartzo tem bordas suturadas a interlobadas. Mica branca tem orientação preferencial constituindo foliação que faz um ângulo com o bandamento. Portanto, concluiu-se que a preservação do quartzo, de origem detrítica, e a ausência de xistosidade na região Norte indicam que a intensidade da deformação durante o metamorfismo nesta área foi mais fraca do que na porção Sul, na qual o quartzo está inteiramente recristalizado e a mica tem orientação preferencial planar. Verifica-se, ainda, que mais a Oeste, no ponto V77, próximo à falha reversa, a foliação metamórfica é também pronunciada, isto é, a intensidade da deformação sinmetamórfica cresce de Norte a Sul e também de Leste a Oeste.

A variação de cor do quartzito é fruto da diversidade mineralógica. A seguir, os tipos de quartzitos, todos apresentando coloração não usual, estão identificados.
Cianita quartzito A rocha é cinza-esverdeada clara. É constituída por $60 \%$ em volume de quartzo, $35 \%$ de cianita e $5 \%$ de mica branca, zircão, rutilo e opacos. A cor levemente esverdeada deve-se à cianita. Possui bandamento de espessura milimétrica, com alternância de bandas de quartzo e de cianita. A cianita é poiquiloblástica, com abundantes inclusões de quartzo. É provável que o bandamento seja o produto metamórfico do acamamento sedimentar primário, pois localmente caracteriza-se como uma estratificação cruzada.

\section{Dumortierita quartzito \pm cianita \pm muscovita}

variação de cor do dumortierita quartzito, que é o mais importante litotipo explotado comercialmente como rocha ornamental, deve-se à irregular distribuição de dumortierita e/ou cianita, as quais se concentram em bandas plano paralelas ou orientadas segundo estratificações cruzadas (Figs. 2A e 2B). Verifica-se, ainda, que a dumortierita também se concentra em zonas de fratura discordantes do bandamento sedimentar (Fig. 2B). As porções compostas predominantemente por quartzo são brancas. A presença
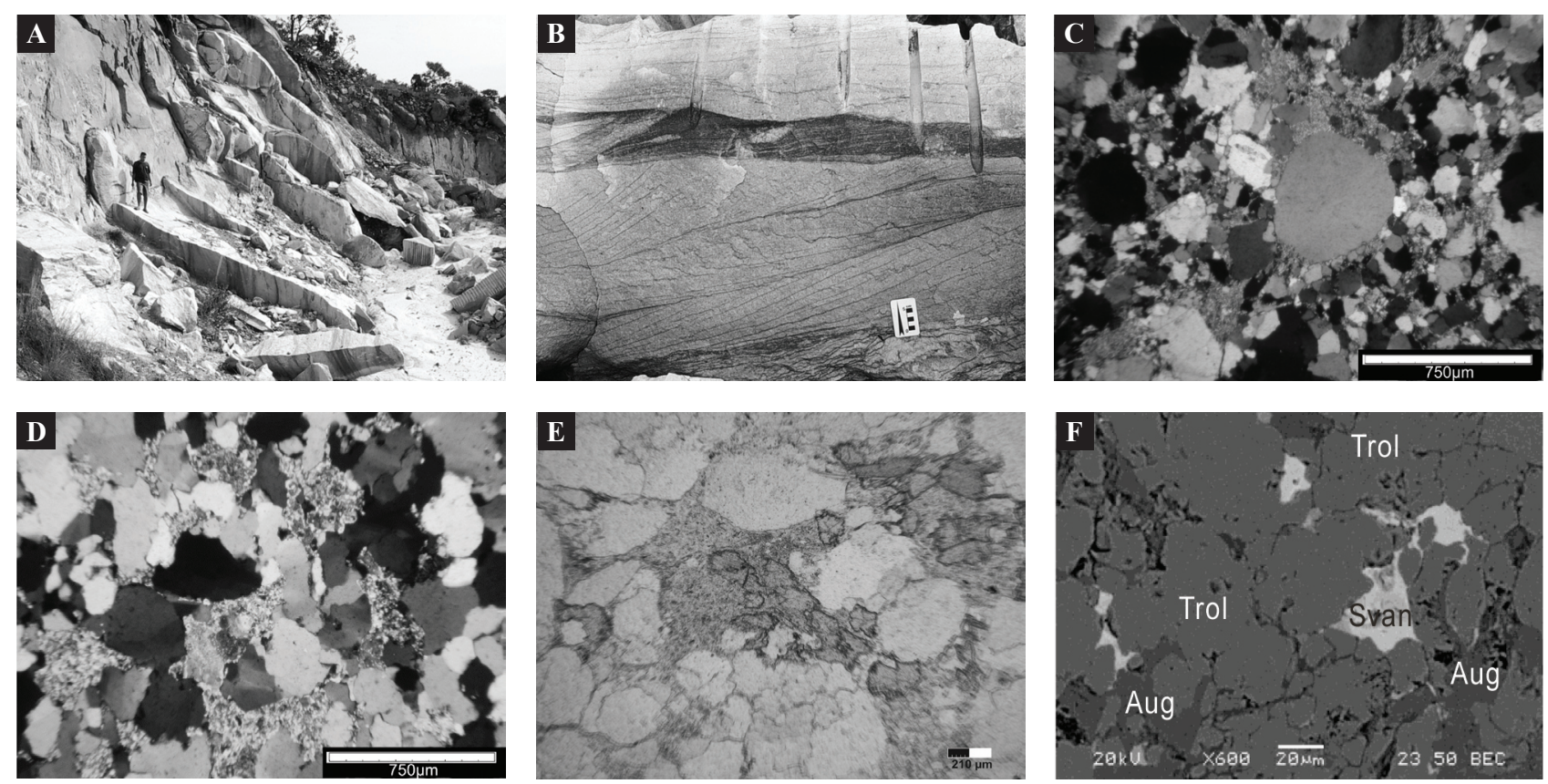

Figura 2 - Fotografias e fotomicrografias do quartzito azul. (A) frente de lavra em horizonte subdecamétrico de quartzito azul da Formação Veredas, situada no segmento central do Espinhaço Setentrional (Ponto V35). (B) vista em corte de horizonte de quartzito azul da Formação Veredas com leitos centimétricos laminados e retrabalhados por ondas no topo, intercalados a metarenitos com estratificação cruzada de médio porte; notar a maior concentração de dumortierita (niveis escuros) ao longo dos planos de estratificação e de fraturas irregulares (Ponto V76). (C) fotomicrografia da porção quartzosa do quartzito azul mostrando grãos arredondados de quartzo, de origem reliquiar detrítica, envolvidos por sericita (amostra V-76). Pol X. (D) fotomicrografia de quartzito verde-azulado com agregados de fosfatos de aluminio (principalmente lazulita), envolvendo grãos de quartzo (amostra V8). Pol $X$. (E) fotomicrografia de metarenito com grãos arredondados de quartzo, cujos interstícios estão preenchidos por dumortierita (alto relevo) e fina mica branca (amostra V76). Pol //. (F) imagem de elétrons retroespalhados do lazulita-trolleita quartzito, mostrando svanbergita-goyazita (Svan), de cor mais clara, e trolleita (Trol) com substituição por filetes de augelita (Aug) mais escura (amostra V8). 
de volumes grandes de dumortierita produz intensa cor azul. Se também ocorrer cianita e/ou muscovita, a coloração tornar-se-á azul-acinzentada ou esverdeada.

O quartzo predomina e o seu teor varia, de amostra para amostra, entre 50 a $85 \%$ em volume. É inequigranular, os grãos maiores $(\sim 1 \mathrm{~mm})$ são arredondados (Figs. 2C e 2E), sugerindo origem sedimentar detrítica, isto é, são remanescentes da rocha sedimentar primária e não foram totalmente recristalizados durante $o$ metamorfismo. Neste caso, a rocha pode ser classificada como quartzo metarenito, que ocorre principalmente na porção Norte da faixa mapeada (Fig. 1, pontos V43 e V76). Nas bordas, pode ser observada parcial recristalização metamórfica em grãos finos, caracterizando textura do tipo núcleo-manto. Principalmente nas amostras localizadas mais ao Sul (V38), mas também na porção central representada na Fig. 1, o quartzo tende a granoblástico poligonal, isto é, sofreu total recristalização metamórfica. A dumortierita é tabular, com bordas franjadas, tem até $1 \mathrm{~mm}$ de comprimento e se concentra em delgadas camadas anastomosadas, quase monominerálicas. Nas lâminas analisadas, o teor fica em torno de 15 a $20 \%$. É fortemente pleocroica em tons de azul e tem cores de interferência que chegam ao vermelho de primeira ordem. Nas porções mais acinzentadas, a cianita chega a $30 \%$ em volume, associando-se ao pequeno teor de dumortierita. Mica branca (10 a 15\%) é muito fina e foi identificada como muscovita (Tab. 1). Pode ocorrer disseminada sob a forma de diminutas palhetas sem orientação preferencial ou em agregados nodulares monominerálicos, que apresentam foliação e fraca crenulação. Essas massas nodulares podem representar o produto metamórfico de intraclastos argilosos do arenito original. A augelita, um fosfato de alumínio $\mathrm{Al}_{2} \mathrm{PO}_{4}(\mathrm{OH})_{3}$, constitui diminutos agregados incolores, com cores de interferência baixas e aspecto lamelar semelhante ao parquete. $\mathrm{O}$ volume foi estimado em aproximadamente $3 \%$. Os minerais acessórios são zircão, mineral opaco e fosfato de alumínio, cério, lantânio, estrôncio e enxofre (Tab. 1, amostra V43), este foi identificado nas imagens de elétrons retroespalhados e em análises químicas como goyazita de cério e lantânio.

Lazulita-trolleíta quartzito A rocha é verdeazulada (azul-piscina), a cor se deve exclusivamente a fosfatos de alumínio, os quais se distribuem homogeneamente, estando ausente a dumortierita. Distingue-se do dumortierita quartzito pela ausência do bandamento sedimentar. O quartzo exibe textura granular interlobada, tipicamente metamórfica, constituindo cerca de $70 \%$ em volume da rocha. Rodeando os grãos de quartzo, têm-se os minerais do grupo dos fosfatos em finos agregados de relevo mais elevado, incolores a levemente azulados e que constituem até $30 \%$ da rocha (Fig. 2D). Foram determinados, quimicamente, quatro tipos de fosfatos

Tabela 1 - Composição química (em \% peso) de trolleita, lazulita e augelita das amostras V8 e V43 e de dados da literatura

\begin{tabular}{|c|c|c|c|c|c|c|c|c|c|c|c|c|c|c|c|c|}
\hline & \multicolumn{5}{|c|}{ Trolleíta } & \multicolumn{5}{|c|}{ Lazulita } & \multicolumn{6}{|c|}{ Augelita } \\
\hline & Trol* & Trol** & Trol $^{4}$ & Trol $^{5}$ & Trol $^{6}$ & Laz* & Laz** $^{* *}$ & $\mathrm{Laz}^{4}$ & $\mathrm{Laz}^{5}$ & $\mathrm{Laz}^{6}$ & Aug* & $\mathrm{Aug}^{4}$ & Aug** & $\mathrm{Aug}^{4}$ & Aug $^{5}$ & $\mathrm{Aug}^{6}$ \\
\hline Óxidos & V8 & V8 & V8 & & & V8 & V8 & V8 & & & V8 & V8 & V43 & V43 & & \\
\hline & $\mathrm{n}=2$ & $\mathrm{n}=18$ & $\mathrm{n}=18$ & & $\mathrm{n}=5$ & $\mathrm{n}=1$ & $\mathrm{n}=4$ & $\mathrm{n}=4$ & & $\mathrm{n}=6$ & $\mathrm{n}=3$ & $\mathrm{n}=3$ & $\mathrm{n}=7$ & $\mathrm{n}=7$ & & $\mathrm{n}=4$ \\
\hline $\mathrm{SiO}_{2}$ & 0,30 & - & - & n.a. & 0,08 & 0,06 & - & - & n.a. & 0,12 & - & - & - & - & n.a. & 0,03 \\
\hline $\mathrm{P}_{2} \mathrm{O}_{5}$ & 48,18 & 50,29 & 47,27 & 47,97 & 48,85 & 47,05 & 49,44 & 46,47 & 46,96 & 48,38 & 41,70 & 36,07 & 40,64 & 35,15 & 35,49 & 35,35 \\
\hline $\mathrm{TiO}_{2}^{2}$ & - & - & - & n.a. & 0,05 & 0,02 & - & - & n.a. & 0,04 & - & - & - & - & n.a. & 0,01 \\
\hline $\mathrm{Al}_{2} \mathrm{O}_{3}$ & 44,27 & 48,36 & 45,46 & 45,94 & 43,82 & 33,51 & 35,91 & 33,76 & 33,74 & 33,56 & 58,30 & 50,43 & 59,36 & 51,35 & 50,99 & 49,76 \\
\hline $\mathrm{Cr}_{2} \mathrm{O}_{3}$ & n.a. & - & - & n.a. & n.a. & n.a. & - & - & n.a. & n.a. & - & - & - & - & n.a. & n.a. \\
\hline $\mathrm{La}_{2} \mathrm{O}_{3}$ & n.a. & - & - & n.a. & n.a. & n.a. & - & - & n.a. & n.a. & - & - & - & - & n.a. & n.a. \\
\hline $\mathrm{Ce}_{2} \mathrm{O}_{3}$ & n.a. & - & - & n.a. & n.a. & n.a. & - & - & n.a. & n.a. & - & - & - & - & n.a. & n.a. \\
\hline $\mathrm{SO}$ & n.a. & - & - & n.a. & - & n.a. & - & - & n.a. & 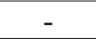 & - & - & - & - & n.a. & - \\
\hline $\mathrm{FeO}^{1}$ & 1,18 & 1,35 & 1,27 & n.a. & 1,22 & 1,26 & 1,30 & 1,22 & n.a. & 15 & - & 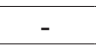 & - & - & n.a. & 0,12 \\
\hline $\mathrm{MgO}$ & - & - & - & n.a. & 0,01 & 12,71 & 13,35 & 12,55 & 13,34 & 12,86 & - & - & - & - & n.a. & 0,04 \\
\hline $\mathrm{CaO}$ & - & - & - & n.a. & 0,02 & 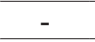 & - & - & & 0,02 & 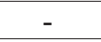 & - & - & - & n.a. & 0,02 \\
\hline $\mathrm{SrO}$ & n.a & - & - & $\mathrm{n}$. & - & n.a. & - & - & & & - & - & - & - & n.a. & 0,02 \\
\hline $\mathrm{a}_{2} \mathrm{O}$ & - & - & - & n.a. & - & - & - & - & & 0,0 & 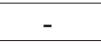 & - & - & - & n.a. & - \\
\hline $\mathrm{K}_{2} \mathrm{O}$ & n.a. & - & - & n.a. & - & - & - & - & n.a. & 0,01 & - & - & - & - & n.a. & 0,06 \\
\hline F & n.a. & - & - & n.a. & n.a. & n.a. & - & - & n.a. & n.a. & - & - & - & - & n.a. & n.a. \\
\hline $\mathrm{B}_{2} \mathrm{O}_{3}$ & n.a. & - & - & n.a. & n.a. & n.a. & - & - & n.a. & n.a. & - & - & - & - & n.a. & n.a. \\
\hline $\mathrm{H}_{2} \mathrm{O}$ & n.a. & - & 6,00 & 6,09 & n.a. & n.a. & - & 6,00 & 5,96 & n.a. & - & 13,5 & - & 13,5 & 13,51 & n.a. \\
\hline Total & $93,93^{2}$ & $100,00^{3}$ & 100,00 & 100,00 & $94,05^{2}$ & $94,53^{2}$ & $100,00^{3}$ & 100,00 & 100,00 & $96,59^{2}$ & $100,00^{3}$ & 100,00 & $100,00^{3}$ & 100,00 & 100,00 & $85,41^{2}$ \\
\hline
\end{tabular}

${ }^{1} \mathrm{Fe}$ como $\mathrm{FeO} ;{ }^{2} \mathrm{Total}$ sem $\mathrm{H}_{2} \mathrm{O} ;{ }^{3} \mathrm{Total}$ recalculado para $100 ;{ }^{4}$ Análise recalculada para 100 incluindo teor de $\mathrm{H}_{2} \mathrm{O}$ estimado; ${ }^{5} \mathrm{Composição}$ teórica calculada para a fórmula geral; ${ }^{R}$ Resultados de Morteani \& Ackermand (2004); n: número de análises; n.a.: não analisado; abaixo do limite de detecção; *análises por microssonda eletrônica; **análises por MEV/SED. 
de alumínio (Tab. 1). O de tamanho maior (até 0,8 $\mathrm{mm}$ ) apresenta maclas polissintéticas, é biaxial negativo com elevado ângulo $2 \mathrm{~V}$ e tem cores de interferência que ficam, em geral, no amarelo-laranja de primeira ordem. As análises químicas mostram que se trata de trolleíta $\mathrm{Al}_{4}\left(\mathrm{PO}_{4}\right)_{3}(\mathrm{OH})_{3}$. De porte menor (em geral $<0,1 \mathrm{~mm})$, aparece a lazulita $(\mathrm{Mg}, \mathrm{Fe})$ $\mathrm{Al}_{2}\left(\mathrm{PO}_{4}\right)_{2}(\mathrm{OH})_{2}$, a qual se caracteriza por leve tonalidade azulada e birrefringência um pouco maior do que a trolleíta, chegando ao início da segunda ordem. Pode aparecer inclusa em trolleíta ou constituindo agregados (Fig. 2D). É o fosfato mais abundante na rocha. Quantitativamente subordinada, tem-se augelita $\mathrm{Al}_{2} \mathrm{PO}_{4}(\mathrm{OH})_{3}$ em finíssimos grãos de cor de interferência mais baixa, cinza a branco de primeira ordem e de difícil identificação na óptica convencional devido ao seu porte reduzido e à quantidade pequena. Aparece como produto de alteração de trolleíta, conforme sugerem as texturas substitucionais nas imagens de elétrons retroespalhados (Fig. 2F). Os minerais acessórios são: zircão, rutilo e fosfato de $\mathrm{Al}, \mathrm{Sr}$ e S, classificado como svanbergita-goyazita (Tab. 1). Esse fosfato ocorre em grãos de porte reduzido, inferior a $25 \mu \mathrm{m}$, facilmente identificados nas imagens de elétrons retroespalhados pela cor mais clara e brilhante (Fig. 2F) decorrente do fato de a massa atômica média dos seus elementos ser mais alta do que a dos outros fosfatos de alumínio. Localmente, verifica-se, ainda, uma alteração da lazulita numa fase constituída praticamente apenas por fósforo, contendo quase $100 \%$ de $\mathrm{P}_{2} \mathrm{O}_{5}$ (em base anidra, conforme análise por MEV). Essa alteração aparece sob a forma de massas compostas de grãos finíssimos com relevo e birrefringência muito altos. No meio das massas podem ocorrer restos dos agregados de lazulita.

Sericita quartzito Rocha de cor verde-grama, com aproximadamente $95 \%$ em volume de quartzo que constitui agregados granoblásticos poligonais até interlobados. Agregados de sericita finíssima perfazem cerca de 5\% da rocha, são levemente esverdeados em lâmina delgada e constituem molduras em torno dos agregados de quartzo. A sericita foi identificada por análise química (Tab. 1), como muscovita com cromo. A cor esverdeada deve-se, provavelmente, ao cromo, cujo teor médio é de 2,5\% em peso de $\mathrm{Cr}_{2} \mathrm{O}_{3}$. Minerais acessórios são zircão e turmalina verde-azulada. Um fosfato de cério e lantânio ocorre em diminutos grãos, de porte inferior a $25 \mu \mathrm{m}$, os quais foram identificados como monazita de cério e lantânio (Tab. 1).
QUÍMICA MINERAL Análises por microssonda eletrônica e por MEV/SED foram obtidas para fosfatos e silicatos selecionados (Tabs. 1 e 2). Como as análises de MEV/SED são sempre totalizadas a $100 \mathrm{em}$ base anidra e a maioria dos fosfatos apresenta teores apreciáveis de $\mathrm{H}_{2} \mathrm{O}$, as análises foram recalculadas incluindo o teor de $\mathrm{H}_{2} \mathrm{O}$ teórico ou da literatura. Verificou-se que, para os elementos maiores e, em parte, para os traços, as análises de MEV/SED se mostraram adequadas para a identificação correta e definição das fórmulas unitárias dos diferentes minerais.

Trolleíta $-\mathbf{A l}_{4}\left(\mathrm{PO}_{4}\right)_{3}(\mathrm{OH})_{3}$ Nas rochas estudadas, a trolleíta é o fosfato encontrado em maior quantidade. Observou-se que os resultados das análises por microssonda eletrônica e por MEV/SED (recalculados considerando um teor de $\mathrm{H}_{2} \mathrm{O}$ de $6 \%$ ) são muito semelhantes (Tab. 1). A trolleíta analisada apresenta, em média, 1,26\% em peso de $\mathrm{FeO}$. Os resultados são semelhantes aos obtidos por Morteani \& Ackermand (2004) para as rochas da mesma região.

Lazulita - (Mg, $\left.\mathbf{F e}^{2+}\right) \mathbf{A l}_{2}\left(\mathbf{P O}_{4}\right)_{2}(\mathbf{O H})_{2}$ Os resultados da Tab. 1 mostram que a lazulita analisada é rica em $\mathrm{Mg}$, isto é, possui uma baixa proporção do membro ferroso scorzalita. Nota-se que os resultados por MEV/SED mostram uma coincidência quase perfeita com os da microssonda. A lazulita da Bahia, reportada por Morteani \& Ackermand (2004), possui teores de $\mathrm{FeO}$ e $\mathrm{P}_{2} \mathrm{O}_{5}$ um pouco maiores do que a lazulita analisada, totalizando os óxidos igual a 96,59 , valor relativamente alto quando considerado o teor de $\mathrm{H}_{2} \mathrm{O}$ de $6 \%$ calculado para a composição teórica.

AUGELITA - $\mathbf{A l}_{2} \mathbf{P O}_{4}(\mathbf{O H})_{3}$ As análises na Tab. 1 foram recalculadas, considerando-se um teor de $\mathrm{H}_{2} \mathrm{O}$ de $13,5 \%$ em peso para a fórmula unitária dada. Verificouse que os resultados são equiparáveis aos reportados na literatura (Morteani \& Ackermand 2004).

\section{Fosfatos de $\mathrm{Al}-\mathrm{Sr}$ da série svanbergita-goyazita} - $\mathrm{SrAl}_{3}\left(\mathrm{PO}_{4}\right)\left(\mathrm{SO}_{4}\right)(\mathrm{OH})_{6}-\mathrm{SrAl}_{3}\left(\mathrm{PO}_{4}\right)_{2}(\mathrm{OH})_{5} \cdot \mathrm{H}_{2} \mathrm{O}$ Apesar do porte reduzido dos grãos $(<25 \mu \mathrm{m})$, os fosfatos de alumínio-estrôncio foram identificados facilmente nas imagens de elétrons retroespalhados, devido ao forte brilho resultante do número atômico mais alto de estrôncio e enxofre (Fig. 2F). Na Tab. 2 verifica-se que os grãos situam-se, quimicamente, entre svanbergita e goyazita, havendo variação considerável na proporção de $\mathrm{SO}_{4}$, isto é, do componente svanbergita de grão para 
grão numa mesma amostra. Nos grãos mais ricos em goyazita, também ocorre pequena quantidade de flúor. $\mathrm{O}$ teor de cálcio, isto é, dos componentes de alumínio e cálcio como crandalita $\left[\mathrm{CaAl}_{3}\left(\mathrm{PO}_{4}\right)\left(\mathrm{HPO}_{4}\right)(\mathrm{OH})_{6}\right]$, que forma uma série isomorfa com a goyazita, ou como woodhouseita $\left[\left(\mathrm{CaAl}_{3}\left(\mathrm{PO}_{4}\right)\left(\mathrm{SO}_{4}\right)(\mathrm{OH})_{6}\right]\right.$, é muito baixo. Isso pode ser decorrente da pobreza em cálcio das rochas ou da ausência de solução sólida com os fosfatos que contêm enxofre, como os analisados no presente trabalho.

Morteani et al. (2001) mostram que, nos fosfatos da região de Diamantina, há solução sólida entre goyazita e crandalita (fosfatos sem enxofre), mas não entre svanbergita e woodhouseita (fosfatos com enxofre). Em relação às análises de Morteani \& Ackermand (2004) para goyazita daquela região, concluiu-se que ela tem um teor de cálcio bem maior do que a do presente trabalho. É provável que as rochas estudadas por Morteani \& Ackermand (2004) sejam mais ricas em cálcio, já que crandalita e apatita também foram encontradas.

$\mathrm{Na}$ amostra V43 ocorre uma variedade rica em cério e lantânio. Estes elementos terras raras (ETRs) podem entrar tanto na svanbergita como na goyazita. No caso da amostra estudada, o baixo teor de enxofre indica tratar-se de goyazita, na qual a quantidade relativamente pequena de estrôncio deve-se ao fato de os ETRs entrarem como substituição no site do estrôncio. Uma variação química complexa foi também descrita por Visser et al. (1997) para crandalita de cério da mesma região, que forma solução sólida com florencita $\left[\mathrm{CeAl}_{3}\left(\mathrm{PO}_{4}\right)\left(\mathrm{PO}_{3} \mathrm{OH}\right)(\mathrm{OH})_{6}\right]$ e goyazita. Ao contrário da goyazita de cério e lantânio do presente trabalho, não foram detectados outros ETR além do cério na crandalita analisada por Visser et al. (1997).

Monazita - (Ce, La)PO $\mathbf{P O}_{4}$ A monazita de cério e lantânio aparece em grãos extremamente pequenos no mica quartzito (amostra V77). A Tab. 2 mostra que esta é rica em cério $\left(\sim 45 \%\right.$ em peso de $\left.\mathrm{Ce}_{2} \mathrm{O}_{3}\right)$ e lantânio $(\sim 16 \%$ em peso de $\mathrm{La}_{2} \mathrm{O}_{3}$ ). Os pequenos teores de silício e alumínio detectados são oriundos de quartzo e fosfato de alumínio adjacentes.

Dumortierita - (Al, _, Ti, $\mathrm{Mg}) \mathrm{Al}_{6} \mathrm{BSi}_{3} \mathrm{O}_{16}(\mathrm{O}, \mathrm{OH})_{2} \mathrm{~A}$ dumortierita é, depois das turmalinas, o mineral de boro mais comum em rochas metamórficas e metassomáticas. No entanto, este elemento, tal como o $\mathrm{H}_{2} \mathrm{O}$, não pode ser determinado nas análises convencionais por microssonda eletrônica ou MEV/SED. Para averiguar a confiabilidade dos resultados reportados na Tab. 2, recalculou-se a média obtida por MEV/SED incluindo 5,9\% de $\mathrm{B}_{2} \mathrm{O}_{3}$ e $0,1 \%$ de $\mathrm{H}_{2} \mathrm{O}$, que representam o teor desses óxidos conforme reportado na literatura (Tab. 1, Grew 1996). O resultado obtido é semelhante ao da microssonda eletrônica, exceto o teor menor de $\mathrm{TiO}_{2}(0,91$ para

Tabela 2 - Composição química (em \% peso) de goyazita, svanbergita, monazita, dumortierita e muscovita das amostras V8, V43 e V77 e de dados da literatura

\begin{tabular}{|c|c|c|c|c|c|c|c|c|c|c|c|c|c|c|c|c|c|}
\hline & \multicolumn{9}{|c|}{ Goyazita (Goy) e svanbergita (Svanb) } & \multicolumn{2}{|l|}{ Monazita } & \multicolumn{3}{|c|}{ Dumortierita } & \multicolumn{3}{|c|}{ Muscovita } \\
\hline & Goy** & Goy & Svanb** & Svanb & Goy** & Goy & $\begin{array}{c}\text { Svanb- } \\
\text { goy }^{7}\end{array}$ & Goy $^{6}$ & Svan $^{6}$ & Mon* & Dum* & Dum** & Dum $^{10}$ & Dum $^{6}$ & Dum $^{11}$ & $\mathrm{Mu}^{* *}$ & $\mathrm{Mu}^{* *}$ \\
\hline Óxidos & $\begin{array}{c}\mathrm{V} 8 \\
\mathrm{n}=3\end{array}$ & $\begin{array}{c}\mathrm{V} 8 \\
\mathrm{n}=3\end{array}$ & $\begin{array}{c}\mathrm{V} 8 \\
\mathrm{n}=3\end{array}$ & $\begin{array}{c}\mathrm{V} 8 \\
\mathrm{n}=3\end{array}$ & $\begin{array}{l}\mathrm{V} 43 \\
\mathrm{n}=2\end{array}$ & $\begin{array}{c}\mathrm{V} 43 \\
\mathrm{n}=2\end{array}$ & & $\mathrm{n}=1$ & $\mathrm{n}=7$ & $\begin{array}{c}\text { V77 } \\
\mathrm{n}=2\end{array}$ & $\begin{array}{l}\mathrm{V} 43 \\
\mathrm{n}=6\end{array}$ & $\begin{array}{c}\mathrm{V} 43 \\
\mathrm{n}=2\end{array}$ & V43 & $\mathrm{n}=5$ & & $\begin{array}{c}\text { V77 } \\
\mathrm{n}=5\end{array}$ & $\begin{array}{l}\mathrm{V} 43 \\
\mathrm{n}=5\end{array}$ \\
\hline $\mathrm{SiO}_{2}$ & - & - & - & - & - & - & n.a. & 0,02 & 0,04 & 1,61 & 30,69 & 33,89 & 31,86 & 31,36 & 28,67 & 48,37 & 46,3 \\
\hline $\mathrm{P}_{2} \mathrm{O}_{5}$ & 32,90 & 28,78 & 23,33 & 20,53 & 30,49 & 26,67 & 15,37 & 33,91 & 21,63 & 36,10 & 0,01 & - & - &.- & 0,64 & - & - \\
\hline $\mathrm{TiO}_{2}$ & - & - & - & - & - & - & n.a. & 0,01 & 0,04 & - & 0,91 & 0,38 & 0,36 & 1,49 & 2,41 & 1,01 & - \\
\hline $\mathrm{Al}_{2} \mathrm{O}_{3}$ & 37,61 & 32,90 & 36,56 & 32,17 & 41,46 & 36,27 & 33,13 & 36,77 & 32,56 & 0,77 & 62,91 & 65,73 & 61,78 & 60,69 & 61,21 & 32,36 & 38,99 \\
\hline $\mathrm{Cr}_{2} \mathrm{O}_{3}$ & - & - & - & - & - & - & n.a. & n.a. & n.a. & - & n.a. & - & - & n.a. & n.a. & 2,45 & - \\
\hline $\mathrm{La}_{2} \mathrm{O}_{3}$ & - & - & - & - & 3,73 & 3,26 & n.a. & n.a. & n.a. & 16,24 & n.a. & - & - & n.a. & n.a. & - & - \\
\hline $\mathrm{Ce}_{2} \mathrm{O}_{3}$ & - & & - & - & 9,27 & 8,11 & n.a. & n.a. & n.a. & 45,06 & n.a. & - & - & n.a. & n.a. & - & - \\
\hline $\mathrm{SO}_{3}$ & 4,90 & 4,29 & 15,24 & 13,41 & 6,26 & 5,48 & 17,34 & 0,47 & 11,32 & - & n.a. & - & - & - & n.a. & - & - \\
\hline $\mathrm{FeO}^{1}$ & - & - & - & - & - & - & n.a. & 0,13 & 0,15 & - & 0,31 & - & - & 0,29 & 0,05 & 3,15 & 2,86 \\
\hline $\mathrm{MgO}$ & - & - & - & - & - & - & n.a. & 0,01 & 0,12 & - & 0,18 & - & - & 0,15 & 0,03 & 1,35 & - \\
\hline $\mathrm{CaO}$ & 2,11 & 1,85 & 1,35 & 1,19 & 0,68 & 0,60 & n.a. & 6,35 & 1,12 & 0,22 & - & - & - & 0,01 & - & - & - \\
\hline $\mathrm{SrO}$ & 19,61 & 17,16 & 23,52 & 20,70 & 8,13 & 7,11 & 22,45 & 11,87 & 18,51 & - & n.a. & - & - & - & n.a. & - & - \\
\hline $\mathrm{Na}_{2} \mathrm{O}$ & - & - & - & - & - & - & n.a. & - & 0,02 & - & - & - & - & - & n.a. & - & 0,21 \\
\hline $\mathrm{K}_{2} \mathrm{O}$ & - & - & - & - & - & - & n.a. & 0,02 & - & - & - & - & - & 0,01 & n.a. & 11,31 & 11,64 \\
\hline $\mathrm{F}$ & 2,88 & 2,52 & - & - & - & - & n.a. & n.a. & n.a. & - & n.a. & - & - & n.a. & - & - & - \\
\hline $\mathrm{B}_{2} \mathrm{O}_{3}$ & - & - & - & - & - & - & n.a. & n.a. & n.a. & - & n.a. & - & 5,9 & n.a. & 5,89 & - & - \\
\hline $\mathrm{H}_{2} \mathrm{O}$ & - & 12,5 & - & 12,0 & - & 12,5 & 11,71 & n.a. & n.a. & - & n.a. & - & 0,1 & n.a. & 0,08 & - & - \\
\hline Total & $100,00^{4}$ & $100,00^{5}$ & $100,00^{4}$ & $100,00^{5}$ & $100,00^{4}$ & $100,00^{5}$ & 100,00 & $89,56^{3}$ & $85,51^{3}$ & $100,00^{4}$ & $94,84^{8}$ & $100,00^{9}$ & 100,00 & $94,00^{8}$ & 98,98 & $100,00^{4}$ & $100,00^{4}$ \\
\hline $\mathrm{P} /(\mathrm{P}+\mathrm{S})^{2}$ & 0,87 & 0,87 & 0,60 & 0,60 & 0,83 & 0,83 & 0,47 & 0,99 & 0,66 & & & & & & & & \\
\hline
\end{tabular}


a microssonda, 0,36 para o MEV) e a não identificação de $\mathrm{FeO}$ e $\mathrm{MgO}$, que ficaram abaixo do limite de detecção. Em relação às análises reportadas por Visser et al. (1997) e por Morteani \& Ackermand (2004, Tab. 1) para dumortierita da mesma região, novamente verificou-se um teor de $\mathrm{TiO}_{2}$ menor para os resultados do presente trabalho.

Muscovita - $\mathrm{KAl}_{2} \mathrm{Si}_{3} \mathrm{AlO}_{10}(\mathrm{OH})_{2}$ No quartzito de cor verde (amostra V77), a causa da cor é a mica, já que a rocha não possui fosfatos, cianita e nem dumortierita, causadores de cor em outras rochas. Trata-se de muscovita que se caracteriza por conter cromo, em média, 2,44\% em peso de $\mathrm{Cr}_{2} \mathrm{O}_{3}$ (em base anidra, Tab. 2), o qual provavelmente é o causador da cor verde. Contém, ainda, $1,01 \%$ de $\mathrm{TiO}_{2}, 3,15 \%$ de $\mathrm{FeO}$ e $1,35 \%$ de $\mathrm{MgO}$. A fórmula unitária desta muscovita pode ser escrita como $\mathrm{K}$ ( $\mathrm{Al}, \mathrm{Cr}, \mathrm{Mg}, \mathrm{Fe})_{2}(\mathrm{Si}, \mathrm{Al})_{4} \mathrm{O}_{10}(\mathrm{OH})_{2}$. A muscovita do dumortierita quartzito (amostra F-26) contém 2,86\% de $\mathrm{FeO}$ e um pouco de sódio, cromo, titânio e magnésio estão abaixo do limite de detecção.

DISCUSSÃO E CONCLUSÕES Poucos estudos existem sobre a origem dos minerais que conferem cores azuladas nos quartzitos da Serra do Espinhaço. Fleischer (1971) concluiu ser o boro um elemento original de metassedimentos e que, após o metamorfismo e a deformação, foi remobilizado, gerando a dumortierita. Cassedanne et al. (1989) propuseram uma origem diagenética ou metamórfica para lazulita da Serra das Veredas (Bahia), por processo de dissociação e re-equilíbrio de fosfatos primários do tipo apatita. Segundo Horn et al. (2000), a mineralização dos fosfatos de alumínio e silicatos de boro no Espinhaço mineiro representa o metamorfismo de paleossolos. Num primeiro estágio, terse-iam depositado areias e outros sedimentos sobre os xistos erodidos da borda da bacia. Houve concentração de alumínio, boro, fósforo e ferro nestes xistos e sedimentos arenosos, devido à atividade vulcânica e ao clima seco e quente nas circunvizinhanças de um mar restrito. Posteriormente, teria ocorrido metamorfismo de fácies xisto verde associado com o fechamento da bacia. Estudos microtermométricos de inclusões fluidas em lazulita da região de Diamantina, por Gatter \& Morteani (1999), resultaram em condições de cristalização da lazulita entre $600^{\circ} \mathrm{C}$ e 6 kbar e $400^{\circ} \mathrm{C}$ e 3 kbar, consideravelmente mais altas do que a fácies xisto verde interpretada pelas paragêneses minerais.

Segundo Morteani \& Ackermand (2004), os protólitos dos quartzitos da região estudada são arenitos marinhos depositados em grandes leques aluviais na costa do rifte Espinhaço, em mar raso ou em ambiente do tipo sabkha. O fósforo teria sido precipitado quimicamente, com oxi-hidróxidos de ferro agindo como coletores do fósforo. Essa hipótese seria corroborada pela frequente associação dos fosfatos com camadas ricas em hematita. Durante a diagênese precoce, ter-se-iam cristalizado hematita e fosfatos de alumínio autigênicos, sendo que o alumínio seria derivado de argilominerais como caulinita. $\mathrm{O}$ boro para a geração de dumortierita ter-se-ia derivado de fontes termais e de minerais de boro detríticos, embora os autores afirmem que não há turmalina detrítica nas rochas por eles estudadas. Para explicar o comportamento antitético dos teores de fosfatos e de dumortierita nas rochas, Morteani \& Ackermand (2004) interpretaram que o aumento do boro levaria à destruição da população de algas ao longo da costa e à redução ou interrupção da acumulação de fósforo biogênico. Essa explicação, no entanto, está em desacordo com a premissa de ter sido o fósforo concentrado por precipitação química e não por atividade biogênica.

Nos quartzitos estudados, no presente trabalho, as principais paragêneses minerais identificadas foram: muscovita + quartzo; cianita + muscovita + quartzo; dumortierita + quartzo \pm cianita \pm muscovita e trolleíta + lazulita + quartzo ( + augelita secundária).

Os quartzitos formaram-se, primariamente, como sedimentos quartzo-arenosos com participação de material rico em Al, possivelmente pelítico. Segundo Danderfer \& Dardenne (2002), a análise do acervo litofaciológico da Formação Veredas e dos processos e sistemas deposicionais envolvidos na sua evolução apontam para um contexto transicional, com influência dos sistemas de leques aluviais, flúvio-eólicos e marinhos rasos na deposição dos sedimentos. Para os autores, esse acervo define o preenchimento inicial do rifte Espinhaço, controlado, sobretudo, por processos tectônicos e com variações eustáticas e aporte sedimentar respondendo às mudanças de nível de base no interior da bacia. Segundo Danderfer et al. (2009), o rifteamento teria ocorrido no Mesoproterozoico, com idade máxima de 1,56 Ga.

Danderfer (2000) enquadrou a sedimentação dessa unidade em um modelo de costa de granulação grossa, rica em cascalho e areia no estágio inicial. No caso, os sedimentos cascalhosos trazidos por rios entrelaçados sofreram retrabalhamento intenso, que é decorrente de fluxos oscilatórios, o que possibilitou a seleção de clastos estáveis para a composição de fácies de conglomerado oligomítico. Os arenitos com seixos, por sua vez, resultaram do retrabalhamento por fluxo oscilatório de parte dos 
sedimentos arenosos trazidos por rios, em um ambiente marinho litorâneo; outra parte deles foi retrabalhada por ventos, formando assim depósitos de dunas costeiras. Em direção ao topo, passaram a dominar arenitos mais bem selecionados, transportados e depositados principalmente por correntes de marés, em condições também litorâneas, possivelmente em um ambiente de planície de maré arenosa. A presença de fácies heterolíticas com estruturas flaser, wavy e linsen constitui feição comum nesse tipo de ambiente. Depósitos tempestíticos episódicos completam o acervo deposicional dessa unidade. É nesse cenário que se depositaram os sedimentos ricos em boro, os quais, posteriormente, vieram a constituir os quartzitos com dumortierita da região. Sua origem é interpretada neste trabalho como vinculada à deposição de sais evaporíticos ricos em boro (boratos), que se fixaram principalmente nos sedimentos finos (lamitos), possivelmente em ambientes lagunares ou em planícies de marés situadas na parte posterior das ilhas barreiras. $\mathrm{O}$ contexto é interpretado por Danderfer (2000) como uma fase do tipo golfo da bacia, com desenvolvimento de evaporitos associado a uma sedimentação litorânea dominada por marés e com vagas tempestíticas episódicas.

Dessa forma, os sedimentos pelito-quartzo-arenosos foram depositados concomitantemente com o boro e o fósforo, embora houvesse episódios com deposição majoritária de material rico em alumínio, que se transformou nas camadas de cianita ou, quando enriquecidas em boro, nas de dumortierita. A distribuição do fósforo foi mais aleatória, pois as porções enriquecidas em fosfatos são de ocorrência menos regular, não podendo ser associadas a níveis correlacionados ao $\mathrm{S}_{0}$, como é o caso da dumortierita. A concentração dos elementos, em especial o boro, que geraram a dumortierita, está condicionada em primeiro lugar ao ambiente de sedimentação, tendo em vista a sua distribuição segundo o acamamento sedimentar primário. No entanto, um episódio posterior levou à remobilização do boro, já que existe dumortierita ao longo de fraturas (Fig. 2B). Tal fato atesta a elevada mobilidade do boro, especialmente quando comparado ao fósforo, já que não se observaram os fosfatos como preenchimento de fraturas. Leeman \& Sisson (1966) mostram que o boro é prontamente mobilizado, tanto por fluidos diagenéticos como metamórficos.

Quanto ao metamorfismo que gerou as paragêneses encontradas, a formação de cianita em metapelitos indica temperaturas superiores a cerca de $400^{\circ} \mathrm{C}$ e $\mathrm{P} \geq 2,5$ kbar (Bucher \& Frey 1994), que é a temperatura em que ocorre a formação de cianita segundo a reação: pirofilita $=$ cianita + quartzo $+\mathrm{H}_{2} \mathrm{O}$.
Em temperaturas entre aproximadamente 500 e $560^{\circ} \mathrm{C}$ (para $\mathrm{P}=4-5 \mathrm{kbar}$ ), a sillimanita passa a formar-se no lugar de cianita e, em pressões mais baixas, o polimorfo de $\mathrm{Al}_{2} \mathrm{SiO}_{5}$ seria andaluzita. Portanto, baseando-se somente na presença de cianita, os quartzitos teriam sido gerados entre 400 e $560^{\circ} \mathrm{C}$, considerando-se pressões entre 2,5 e 5 kbar. Uma estimativa mais acurada das condições metamórficas baseia-se na presença de trolleíta, que aparece recortada por filetes de augelita (Fig. 2F), textura típica de transformações retrometamórficas acompanhadas da infiltração de fluido aquoso. Uma possível reação retrometamórfica de formação da augelita à custa de trolleíta ocorre numa temperatura de cerca de $475^{\circ} \mathrm{C}$ e $\mathrm{P} \geq 3,5 \mathrm{kbar}$ (Wise \& Loh 1976): trolleíta + cianita $+\mathrm{H}_{2} \mathrm{O}=$ augelita + quartzo.

Portanto, a trolleíta foi gerada acima das condições metamórficas da reação. Logo, os quartzitos com cianita e trolleíta formaram-se em temperaturas superiores a $475{ }^{\circ} \mathrm{C}$ (para $\mathrm{P} \geq 3,5 \mathrm{kbar}$ ), temperatura abaixo da qual a trolleíta se transforma em augelita e inferior a $560^{\circ} \mathrm{C}$, temperatura máxima em que a cianita é o polimorfo de $\mathrm{Al}_{2} \mathrm{SiO}_{5}$ em metapelitos, para $\mathrm{P}=5 \mathrm{kbar}$. Essas condições caracterizam a fácies xisto verde superior, transição para a fácies anfibolito. Geotermometria baseada em isótopos de oxigênio do par quartzo-hematita, realizada por Morteani \& Ackermand (2004) em rochas da região, resultaram em $\mathrm{T}=475^{\circ} \mathrm{C}$, o que está de acordo com o limite inferior de temperatura interpretado.

Especialmente na porção setentrional da região estudada, a preservação de quartzo em grãos arredondados, isto é, de origem sedimentar detrítica, indica que o metamorfismo não possibilitou a completa recristalização desse mineral. Esse tipo de microestrutura reliquiar não foi, no entanto, descrita por Morteani \& Ackerman (2004), os quais descrevem exclusivamente quartzo granoblástico poligonal, com junções tríplices de $120^{\circ}$. A conservação de feições sedimentares em rochas de metamorfismo regional de fácies xisto verde a anfibolito pode acontecer se o processo deformacional for de baixa magnitude durante o evento tectonometamórfico. Nas rochas estudadas, além do quartzo detrítico, a preservação local de bandamento mineralógico refletindo uma estratificação cruzada de origem sedimentar reforça a interpretação do processo metamórfico acompanhado de incipiente pressão dirigida.

Resumindo, conclui-se que, além de cianita, dumortierita, muscovita, zircão e rutilo, diversos fosfatos (lazulita, trolleíta, augelita, svanbergita-goyazita e monazita) são encontrados em quartzitos de coloração azulada a esverdeada da Serra da Vereda, na Bahia. Em 
algumas amostras esverdeadas, a causa da cor é muscovita cromífera, enquanto que, em outras, são os fosfatos os causadores da cor, sendo que a dumortierita é responsável pela cor azul-celeste. É notável a variação química de alguns fosfatos como a svanbergita-goyazita, que incorporam teores apreciáveis de ETR. As condições metamórficas foram da fácies xisto verde superior, em temperaturas entre 475 e $560^{\circ} \mathrm{C}$ e pressões superiores a 3,5 kbar. A preservação local de feições sedimentares, como grãos arredondados de quartzo detrítico e estratificações cruzadas, indica que a deformação durante o evento tectonometamórfico foi localmente incipiente.

AGRADECIMENTOS À Fundação de Amparo à Pesquisa do Estado de Minas Gerais (Fapemig), processo CEX-864/96, pelo financiamento dos trabalhos de campo dentro do projeto "Tectônica e Estratigrafia do Espinhaço Setentrional".

\section{Referências}

Alkmim F.F., Brito Neves B.B., Alves J.A.C. 1993. Arcabouço tectônico do cráton do São Francisco - uma revisão. In: Dominguez J.M. \& Misi A. (eds.) O Cráton do São Francisco. Salvador, SBG/SGM/CNPq, p. 45-62.

Almeida F.F.M. 1977. O Cráton do São Francisco. Revista Brasileira de Geociências, 7:349-364.

Bucher K. \& Frey M. 1994. Petrogenesis of Metamorphic Rocks. Springer-Verlag, Berlin, 318 p.

Cassedanne J.P., Cassedanne J.O., Carvalho H.F. 1989. Origine de lazulites liées à dês accidents ferrifères dans des quartzites à dumortierite (Serra da Vereda, Bahia, Brésil). Anais Academia Brasileira de Ciências, 61:59-72.

Cassedanne J.P. \& Franco R.R. 1966. Indices de dumortiérite de la Serra da Vereda. Municipes de Macaúbas et de Boquira, Etat de Bahia. Anais da Academia Brasileira de Ciências, 38:47-53.

Danderfer A. 2000. Geologia Sedimentar e Evolução Tectônica do Espinhaço Setentrional, Tese de Doutorado, Universidade de Brasília, Brasília, 498 p.

Danderfer A. \& Dardenne M.A. 2002. Tectonoestratigrafia da bacia Espinhaço na porção centro - norte do cráton do São Francisco: registro de uma evolução poliistórica descontínua. Revista Brasileira de Geociências, 32:449-460.

Danderfer A., de Waele B., Pedreira A.A.J., Nalini Jr. H.A. 2009. New geochronological constraints on the geological evolution of Espinhaço basin within the São Francisco craton - Brazil. Precambrian Research, 170:116-128.

Fleischer R. 1971. Observações geológicas sobre a dumortierita da Serra das Veredas. Mineração $e$ Metalurgia, 54:21-24.

Gatter I. \& Morteani G. 1999 The fluid inclusions in the gem-quality lazulite from the Bandeirinha formation (Diamantina, Minas Gerais, Brazil). Zeitschrift der Deutschen Gemmologischen Gesellschaft, 48:65-76.

Grew E.S. 1996. Borosilicates (exclusive of tourmaline) and boron in rock-forming minerals in metamorphic environments. In: Grew E. S. \& Anovitz L. M. (eds.) Boron Mineralogy, Petrology and Geochemistry. Mineralogical Society of America, 33:387-502.

Horn A.H., Knauer G., Neves S.C. 2000. Das Vorkommen von Aluminiumphosphaten, Bormineralen und organischen Konkretionen in den Paläoboden-Bildung am Kontakt zwischen der Rio Paraúna und Espinhaço Supergruppe zwischen Gouveia und Diamantina, Minas Gerais, Brasilien. Münchner Geologische Hefte, A28:99-106.

Horn A.H., Morteani G., Ackermand D. 1996. Significado da ocorrência de fosfatos e boratos de alumínio no contato entre os supergrupos Rio Paraúna e Espinhaço na região de Diamantina, Minas Gerais, Brasil. Geonomos, 4:1-10.

Leeman W.P. \& Sisson V.B. 1996. Geochemistry of boron and its implications for crustal and mantle processes. In: Grew E. S. \& Anovitz L. M. (eds.) Boron Mineralogy, Petrology and Geochemistry, Mineralogical Society of America, 33:117-163.

Morteani G. \& Ackermand D. 2004. Al-phosphate and Al-borosilicate-bearing metaquartzites of the northern Serra do Espinhaço (State of Bahia, Brazil). Mineralogy and Petrology, 80:59-81.

Morteani G., Ackermand D., Horn A.H. 2001. Aluminiumphosphates and borosilicates in muscovite-kyanite metaquartzites near Diamantina (Minas Gerais, Brazil): Petrogenetic implications. Periodico di Mineralogia, 70:111-129.

Moutinho da Costa L.A. \& Silva W.G. 1980. Projeto Santo Onofre, mapeamento geológico. Rio de Janeiro, TRISERVICE, Convênio DNPM/CPRM. 21v., v.1, Relatório Final.

Schobbenhaus C. 1996. As tafrogêneses superpostas Espinhaço e Santo Onofre, Estado da Bahia: revisão e novas propostas. Revista Brasileira de Geociências, 26:265-276.

Schobbenhaus C. 1972. Relatório geral sobre a geologia da região setentrional da Serra do Espinhaço - Bahia Central. Recife, SUDENE/DRN/DG, 91 p., Série Geologia Regional 19.

Visser D., Felius R.O., Moree M. 1997. Augelite and cerian crandallite in dumortierite quartzite, Vaca Morta quarry, Vereda range, Macaúbas, Bahia, Brazil. Mineralogical Magazine, 61:607-609.

Wise W.S. \& Loh S.E. 1976. Equilibria and origin of minerals in the system $\mathrm{Al}_{2} \mathrm{O}_{3}-\mathrm{AlPO}_{4}-\mathrm{H}_{2} \mathrm{O}$. American Mineralogist, 61:409-413.

Manuscrito ID: 17896 Recebido em: 01/07/2010 Aprovado em: 07/03/2012 